\title{
A review of sepsis-induced cardiomyopathy
}

\author{
Ryota Sato ${ }^{*}$ and Michitaka Nasu
}

\begin{abstract}
Sepsis-induced cardiomyopathy is a reversible myocardial dysfunction that typically resolves in 7-10 days. It is characterized by left ventricular dilatation and depressed ejection fraction. However, many uncertainties exist regarding the mechanisms, characteristics, and treatments of this condition. Therefore, this review attempts to summarize our current knowledge of sepsis-induced cardiomyopathy.
\end{abstract}

Keywords: Sepsis-induced cardiomyopathy, Septic cardiomyopathy, Cardiac depression in sepsis

\section{Introduction}

Sepsis is a dysregulated systemic inflammation caused by infections involving various organs. Sepsis-induced cardiomyopathy is a complication of severe sepsis and septic shock first described by Parker et al. in 1984 as a reversible myocardial depression that occurs in patients with septic shock [1]. In sepsis-induced cardiomyopathy, the myocardium is functionally and structurally injured by inflammatory cytokines and mitochondrial dysfunction. However, our understanding regarding this condition remains incomplete. Recently, the development of tools, including echocardiography, has made it possible to visualize the hemodynamics of sepsis-induced cardiomyopathy. Sepsis-induced cardiomyopathy has three characteristics: left ventricular dilatation, depressed ejection fraction, and recovery in 7-10 days. Also, advances in molecular biology have made understanding the mechanisms of sepsis-induced cardiomyopathy possible (Fig. 1). Chemical mediators, including endotoxins, cytokines, and nitric oxide, appear to be the main mediators of sepsis-induced cardiomyopathy. The treatment strategy of sepsis-induced cardiomyopathy is the same with the adequate treatment of sepsis without cardiomyopathy. Although dobutamine is recommended in current guidance, recent trials have demonstrated that in patients with sepsis, it does not improve the prognosis and may have adverse effects. Here, we discuss the mechanisms, characteristics, and treatments of sepsis-induced cardiomyopathy.

\footnotetext{
* Correspondence: st051035@gmail.com

Department of Emergency and Critical Care Medicine, Urasoe General Hospital, 4-16-1, Iso, Urasoe, Okinawa, Japan
}

\section{Review}

Characteristics of sepsis-induced cardiomyopathy

In 1984, Parker et al. reported decreased ejection fraction and increased end-diastolic volume in septic shock survivors. These changes in left ventricular function were of rapid onset and reversed over 7-10 days in survivors; however, they were less profound in those who died $[1,2]$. Moreover, Vieillard et al. demonstrated the mortality rate among patients in a hyperkinetic state to be significantly higher than that among patients in either a hypokinetic or normal-output state (100 vs 43 and $24 \%$ ) [3]. Conversely, a recent meta-analysis suggested that ventricular dysfunction or dilatation in patients with sepsis was not associated with lower mortality [4]. It suggested that mortality does not depend on whether the patients have sepsis-induced cardiomyopathy or not; however, it depends on whether the patient's heart is hyperkinetic or not. Because patients with sepsis-induced cardiomyopathy tend to be either hypokinetic or normokinetic but not hyperkinetic, in patients with sepsis-induced cardiomyopathy, the outcomes may be better than in patients without sepsis-induced cardiomyopathy. Larger studies are needed to clarify whether sepsis-induced cardiomyopathy is associated with improved outcomes.

Sepsis also triggers takotsubo cardiomyopathy, also known as stress cardiomyopathy, apical ballooning syndrome, or broken-heart syndrome, which is different from sepsis-induced cardiomyopathy. Takotsubo cardiomyopathy typically occurs when the contractile function of the midto-apical segments of the left ventricle is depressed and there is hyperkinesis of basal walls, producing a balloonlike appearance of the distal ventricle. Several studies have reported that this syndrome is induced by increased 


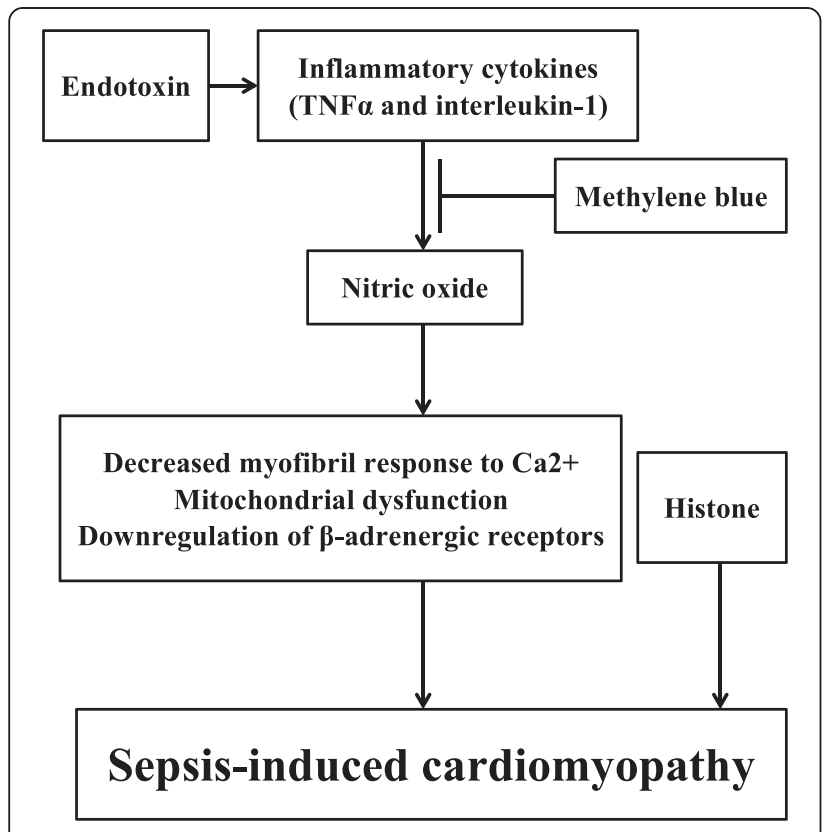

Fig. 1 Mechanisms of sepsis-induced cardiomyopathy. Endotoxins cause depressed cardiac contractility, which is mediated by enhanced nitric oxide (NO) production. Tumor necrosis factor and interleukin-1 $\beta$ also contribute to $\mathrm{NO}$ overproduction. $\mathrm{NO}$ is believed to act in the heart by decreasing myofibril response to calcium, inducing mitochondrial dysfunction, and downregulating $\beta$-adrenergic receptors. These reactions lead to sepsis-induced cardiomyopathy. Methylene blue, an inhibitor of the NO pathway, counteracts the myocardial depression. Histones occur inside the nucleus and can be released into circulation because of extensive inflammation and cellular death during sepsis. Since cardiac dysfunction can be ameliorated by anti-histone antibodies in a septic mouse model, histones may be implicated in the pathophysiology of sepsis-induced cardiomyopathy

catecholamine levels. In takotsubo cardiomyopathy, the left ventricular function usually returns to normal within a few weeks. At a cellular level, changes were shown to be reversible with normalization of the left ventricular ejection fraction, including the cytoskeletal protein derangements, increase in extracellular matrix proteins, and accumulation of intracellular glycogen [5]. Although sepsis and septic shock can trigger takotsubo cardiomyopathy, the etiology and myocardial alterations appear to be different from those of sepsis-induced cardiomyopathy. In sepsis-induced cardiomyopathy, there is global ventricular dysfunction and dilated left ventricle without regional dysfunction. In takotsubo cardiomyopathy, there is typically regional dysfunction, especially characterized by apical ballooning mimicking acute coronary syndrome. Therefore, the accurate diagnosis of takotsubo cardiomyopathy requires coronary angiography to rule out acute coronary syndrome. In addition, many reports on takotsubo cardiomyopathy have mentioned various underlying diseases; this suggests that the pathophysiology of takotsubo cardiomyopathy is not specific to one particular disease. For these reasons, sepsis-induced cardiomyopathy and takotsubo cardiomyopathy are two different entities.

Despite the lack of diagnostic criteria for sepsis-induced cardiomyopathy to date, it is known to have three characteristics. The first is left ventricular dilatation with normal or low filling pressure. This probably occurs due to an increase in the left ventricular compliance, which was first described in patients with septic shock in 1984 [1]. Later, another study of the left ventricle response to volume loading showed that there was an abnormal increase in left ventricular end-diastolic volume in sepsis survivors, implying increased ventricular compliance [6]. The second characteristic is depressed ejection fraction. Parker et al. reported that end-diastolic and systolic ventricular volumes were increased but with normal or elevated stroke volume and cardiac index in septic shock survivors. In this study, although the number of patients is less, these results suggest that decreased ejection fraction may be caused by ventricular dilatation and not by decreased stroke volume. Because ejection fraction is defined as the stroke volume divided by the end-diastolic ventricular volume, the denominator increases as the ejection fraction decreases [7]. Vincent et al. demonstrated that the left and right ventricular ejection fractions are depressed in patients with septic shock [8]. Other studies support this result and have shown the development of right ventricular dilatation $[6,9,10]$. The third characteristic of sepsis-induced cardiomyopathy is that it should normalize within $7-10$ days $[1,11,12]$. In sepsis-induced cardiomyopathy diagnosis, the first and second characteristics are particularly important and easy to detect using echocardiography. Thus, echocardiography in sepsis management is the most important thing for diagnosing sepsis-induced cardiomyopathy.

B-type natriuretic peptide (BNP), a diuretic hormone, is released from ventricular myocardium in response to cardiac wall stretch. Recent observational study demonstrated that sepsis-induced cardiomyopathy is associated with BNP rise, although not independently, whereas left ventricular filling pressures do not correlate with the BNP levels [13]. In this study, the author concluded that the severity of critical illness, rather than sepsis-induced cardiomyopathy, is probably the main determinant of BNP rise in critical patients with sepsis. For this reason, BNP should not be used as a predictive marker of sepsis-induced cardiomyopathy.

Troponin is a very sensitive and specific protein of myocardial damage and often used for the diagnosis of acute coronary syndrome (ACS). Troponin elevation is common in septic shock patients, and it was estimated that $43-85 \%$ of patients with sepsis showed cardiac troponin I elevation [14-16]. Bessiere et al. performed a meta-analysis and reported that troponin elevation is associated with a higher risk of death among patients with 
sepsis [17]. However, the use of troponin to diagnose sepsis-induced cardiomyopathy is limited because there are many causes such as ACS and low renal function that affect troponin levels.

\section{The mechanisms of sepsis-induced cardiomyopathy}

Two possible causative mechanisms have been proposed to explain sepsis-induced cardiomyopathy. First, myocardial ischemia resulting from inadequate coronary blood flow has been proposed on the basis of a study in animals [18]. Second, there are strong arguments that chemical mediators, such as endotoxins, cytokines, and nitric oxide, are causative. To determine whether myocardial depression in humans with septic shock was associated with reduced coronary flow, a study was conducted that used coronary sinus thermodilution catheters to measure coronary flow and myocardial metabolism in seven patients [19]. Myocardial depression was observed in four of the seven patients who had coronary flow similar to or higher than that of controls and similar to that of other three patients. Therefore, reduced coronary flow may not contribute to the pathogenesis of sepsis-induced cardiomyopathy.

Concerning the role of chemical mediators, there are stronger arguments to support their role in sepsis-induced cardiomyopathy. Anthony et al. demonstrated that endotoxin administration to controls caused the left ventricular function to become depressed [20], with left ventricular end- and end-systolic volume indexes increasing by 18 and $24 \%$, respectively. Flesch et al. also demonstrated that exposure of the myocardium to endotoxins caused depressed cardiac contractility, which was mediated by enhanced inducible nitric oxide synthase activity and nitric oxide release [21]. In 1985, Parriio et al. demonstrated in vitro that myocardial cell shortening was reduced by exposure to the serum of patients with sepsis [22]. The same team later showed that this response was caused by tumor necrosis factor alpha (TNF- $\alpha$ ) [23], which was confirmed when Vincent et al. demonstrated that anti-TNF antibody administration improved ventricular function without changing the cardiac filling pressure [24]. In a more recent study, interleukin-1 $\beta$ has also been implicated [25], further supporting cytokine's role in sepsis-induced cardiomyopathy.

Kumar et al. have suggested that cytokine's effect on cardiac myocytes results from an increase in both intracellular cyclic guanosine monophosphate and nitric oxide [26]. Because the half-lives of TNF and interleukin-1 $\beta$ are less than $6 \mathrm{~h}$, nitric oxide appears to have an important contributory role in the pathogenesis of sepsis-induced cardiomyopathy. Nitric oxide is thought to act in the heart by decreasing myofibril response to calcium [27], inducing mitochondrial dysfunction [28], and downregulating $\beta$ adrenergic receptors $[28,29]$. Some studies reported that the severity of cardiac dysfunction and mortality can be related to nitric oxide overproduction and mitochondrial dysfunction [30-32]. Larche et al. demonstrated that mitochondrial dysfunction in sepsis is causative rather than epiphenomenal and relevant in terms of myocardial dysfunction in sepsis [33]. In 2001, Kirov et al. evaluated the effects of continuous infusion of methylene blue, an inhibitor of the nitric oxide pathway, on the hemodynamics and organ function of patients with septic shock. They reported that continuous infusion of methylene blue counteracted the myocardial depression, maintained oxygen transport, and reduced the need for concurrent adrenergic support [34]. Later, in a systematic review, Kwok et al. reported that methylene blue administration during sepsis increased the mean arterial pressure and systemic vascular resistance while decreasing the vasopressor requirement [35].

A recent study demonstrated that high-circulating histone levels were significantly associated with new-onset left ventricular dysfunction and arrhythmias in patients with sepsis with no previous cardiac dysfunction [36]. However, because histones occur inside the nucleus and can be released into circulation because of extensive inflammation and cellular death during sepsis, it is unclear whether the circulating histones are the cause or the result of sepsis-induced cardiomyopathy. Further research is warranted to decide the role of circulating histones in the pathogenesis of sepsis-induced cardiomyopathy.

Although the reason why sepsis-induced cardiomyopathy resolves within 7-10 days is poorly understood, the mechanisms proposed in this section appear to be critical. In particular, chemical mediators, such as endotoxins and cytokines, are currently regarded as the most likely cause of sepsis-induced cardiomyopathy. However, the mechanism of myocardial recovery in sepsis-induced cardiomyopathy is poorly understood, and further research is clearly needed.

\section{Treatments for sepsis-induced cardiomyopathy}

In 2001, Rivers et al. reported that early goal-directed therapy was effective for severe sepsis management. Although this strategy has become a standard therapy worldwide, the original study was only a small singlecenter study [37]. The ProCESS [38] and ARISE [39] trials (in 2014) and the ProMiSe trial [40] (in 2015) have since demonstrated that early goal-directed therapy did not improve outcomes compared with usual care. There is a widespread agreement that standard treatment for sepsis should focus on infection control and optimization of hemodynamic parameters by fluid resuscitation and vasopressor therapy. This strategy is also recognized as the standard therapy for sepsis-induced cardiomyopathy. Noradrenaline is recommended as a first-line vasopressor; however, some studies reported that vasopressin also may be effective for septic shock. Russell et al. suggested that 
low-dose vasopressin may reduce the mortality of patients with less severe septic shock, although there was no significant difference between vasopressin and noradrenaline in the 28- and 90-day mortality of all patients with septic shock [41]. From this finding, current guidance describes that low-dose vasopressin can be added to noradrenaline with the intent of either raising mean arterial pressure or decreasing noradrenaline dosage; however, low-dose vasopressin is not recommended as a single vasopressor [42]. Mehta et al. reported that troponin, CK, and ECG are not different in patients with septic shock who are treated with noradrenaline and vasopressin [43]. This finding suggests that vasopressin also may be effective for the management of sepsis-induced cardiomyopathy. However, further study is warranted to confirm the effectiveness of vasopressin.

Current guidance recommends using dobutamine [42] to increase the cardiac index [44]. However, Gattinoni et al. reported that hemodynamic therapy with dobutamine and dopamine to achieve supranormal values for the cardiac index failed to reduce morbidity or mortality among critically ill patients [45]. Michelle et al. also demonstrated that the use of dobutamine to boost the cardiac index did not improve the outcome of critically ill patients [46]. Furthermore, Wilkman et al. reported that the use of dobutamine was associated with increased 90-day mortality from septic shock [47], while Hernandez et al. demonstrated that dobutamine did not improve sublingual microcirculatory, metabolic, hepatosplanchnic, or peripheral perfusion parameters in patients with septic shock [48].

Lyte et al. suggested that the ability of inotropic catecholamines to stimulate bacterial proliferation and biofilm formation might be an etiological factor in the development of intravascular catheter colonization and catheter-related infection [49]. This effect of inotropic catecholamines does not seem to be limited to only coagulase-negative Staphylococcus but also other gramnegative bacteria. The growth of these bacteria and production of virulence are associated with inotropic catecholamines [49]. Thus, inotropic catecholamines, such as dobutamine, may have adverse effects in patients with septic shock, and the decrease in $\beta$-adrenergic response in patients with sepsis-induced cardiomyopathy may be a protective mechanism to these effects. Morelli et al. suggest that $\beta$-blockade could be associated with reductions in the heart rate without adverse effects and that this could help to improve survival [50]. Although the mortality in the control group of their study was high, the study provided interesting preliminary data suggesting that $\beta$-blockade may be effective in septic shock treatment. For these reasons, despite the beneficial effects of dobutamine, it appears that excessive increases in sympathetic tone during sepsis can create adverse effects.
Levosimendan can increase contractile myofilament sensitivity to calcium and is a positive inotropic drug. Levosimendan sensitizes troponin $\mathrm{C}$ to calcium in a calcium concentration-dependent manner; this increases the effects of calcium on myofilaments during systole. This sensitization is diminished by decreasing calcium concentration level during diastole, and thus, diastolic relaxation remains largely unaffected. In contrast to other inotropic agents, levosimendan does not cause arrhythmias or increase the oxygen consumption. It also opens the ATP-sensitive potassium channels causing smooth muscle membrane hyperpolarization which leads to vasodilation. A meta-analysis evaluated the use of levosimendan in septic shock [51] and reported that it was associated with reduced mortality when compared with standard inotropic therapy. Although levosimendan is also an inotropic agent, it does not stimulate $\beta$-adrenergic receptor. This may be the reason why levosimendan can be effective to the patients with septic shock, despite dobutamine seems to create adverse effect in the patients with septic shock. To confirm this finding, a larger multicenter randomized trial is needed to assess the effectiveness of levosimendan in sepsis-induced cardiomyopathy.

Intra-aortic balloon pumping (IABP) is expected to increase the cardiac output and reduce the dosage of a vasopressor. Solomon et al. demonstrated that in a canine model of severe septic shock with a low cardiac index, IABP prolongs survival time and lowers vasopressor requirements [52]. Nakamura et al. reported two cases of severe sepsis-induced cardiomyopathy with refractory shock [53]. To our knowledge, this is the only report in which polymyxin B-immobilized fiber column-direct hemoperfusion (PMX-DHP) and IABP were used for the management of sepsis-induced cardiomyopathy. Although the authors suggested their use in sepsis-induced cardiomyopathy, their effectiveness and safety are not yet developed and their use in the management of septic shock are currently at an experimental stage. For example, a recent multicenter randomized controlled trial demonstrated a non-significant increase in mortality and no improvement in organ failure with PMX-DHP compared to the conventional treatment in patients with septic shock due to peritonitis [54]. There are some case reports of the successful use of veno-arterial extracorporeal membrane oxygenation (ECMO) as the last rescue therapy to unresponsive severe cardiogenic shock in patients with sepsisinduced cardiomyopathy. We searched PubMed (January 1990 to September 2015) for English language articles for sepsis-induced cardiomyopathy treated with veno-arterial ECMO. The keywords "sepsis" OR "septic shock" AND "extracorporeal membrane oxygenation" were used and we carefully reviewed the articles found. The adult patients with sepsis-induced cardiomyopathy who received venoarterial ECMO support are listed in Table 1 [55-63]. This 
Table 1 Reported cases of the patients with sepsis-induced cardiomyopathy who received veno-arterial extracorporeal membrane oxygenation support

\begin{tabular}{|c|c|c|c|c|}
\hline Article & Age & Sex & Infection & Survival \\
\hline Pořízka M et al. 2015 [55] & 31 & M & Necrotizing fasciitis & + \\
\hline Fujisaki N et al.2014 [56] & 27 & $\mathrm{~F}$ & CA pneumonia & + \\
\hline Endo A et al. 2014 [57] & 41 & M & Purpura fulminans & - \\
\hline Bréchot N et al. 2013 [58] & 33 & M & CA pneumonia & + \\
\hline Bréchot N et al. 2013 [58] & 62 & M & CA pneumonia & + \\
\hline Bréchot N et al. 2013 [58] & 31 & $\mathrm{~F}$ & Acute cholecystitis & + \\
\hline Bréchot N et al. 2013 [58] & 33 & $\mathrm{~F}$ & Aspiration pneumonia & + \\
\hline Bréchot N et al. 2013 [58] & 48 & $\mathrm{~F}$ & CA pneumonia & - \\
\hline Bréchot N et al. 2013 [58] & 66 & M & Peritonitis after liver transplant & - \\
\hline Bréchot N et al. 2013 [58] & 59 & M & CA pneumonia & + \\
\hline Bréchot N et al. 2013 [58] & 52 & M & CA pneumonia & - \\
\hline Bréchot N et al. 2013 [58] & 28 & $\mathrm{~F}$ & CA pneumonia & + \\
\hline Bréchot N et al. 2013 [58] & 35 & M & Aspiration pneumonia & + \\
\hline Bréchot N et al. 2013 [58] & 28 & $\mathrm{~F}$ & Aspiration pneumonia & + \\
\hline Bréchot N et al. 2013 [58] & 52 & $\mathrm{~F}$ & Nosocomial pneumonia & + \\
\hline Bréchot N et al. 2013 [58] & 57 & $\mathrm{~F}$ & Pharyngitis & + \\
\hline Bréchot N et al. 2013 [58] & 48 & M & CA pneumonia & - \\
\hline Hagiwara et al. 2013 [59] & 69 & M & Klebsiella bacteremia & + \\
\hline Firstenberg MS et al. 2010 [60] & 18 & M & Necrotizing fasciitis & + \\
\hline Firstenberg MS et al. 2010 [60] & 39 & $\mathrm{~F}$ & Necrotizing fasciitis & + \\
\hline MacLaren G et al. 2010 [61] & 29 & $\mathrm{~F}$ & H1N1 influenza & + \\
\hline Vohra HA et al. 2009 [62] & 18 & M & Mediastinitis after Ravitch procedure & + \\
\hline McLauren G et al. 2004 [63] & 22 & M & Vertebral osteomyelitis & + \\
\hline
\end{tabular}

$C A$ community acquired, $M$ male, $F$ female

strategy may provide time for antibiotics to work effectively. If both septic and cardiogenic factors contribute to the pathophysiology of shock, veno-arterial ECMO may improve the mortality of the most severe group. However, the experience of the use of ECMO in patients with septic shock is very limited. Moreover, the management of patients who need ECMO is very complex; thus, a well-experienced team should use it in a specialized center [64]. For these reasons, to date, mechanical support with IABP or ECMO seems not to be a standard therapy, although it may be the last option for unresponsive severe cardiogenic shock due to sepsis-induced cardiomyopathy.

\section{Summary of our current knowledge}

Sepsis-induced cardiomyopathy is characterized by left ventricular dilatation and depressed ejection fraction that typically normalize within 7-10 days. Our current understanding is that sepsis-induced cardiomyopathy is induced by endotoxins and cytokines and that the initial management should be the same as for septic shock without cardiomyopathy. However, the lack of quality evidence that dobutamine improves survival and the concerning reports that it may adversely affect outcomes in patients with sepsis imply that the routine use of dobutamine should no longer be recommended. In the near future, levosimendan or mechanical support with ECMO may be developed as a therapeutic option, but further study is needed to confirm whether it is truly effective in sepsis-induced cardiomyopathy.

\section{Abbreviations}

ECMO: extracorporeal membrane oxygenation; IABP: intra-aortic balloon pumping; PMX-DHP: polymyxin B-immobilized fiber column-direct hemoperfusion; TNF: tumor necrosis factor.

\section{Competing interests}

The authors declare that they have no competing interests.

Authors' contributions

MN and RS helped in the draft of the manuscript. Both authors read and approved the final manuscript.

\section{Acknowledgements}

We appreciate Tadaaki Takada, M.D., for helping to draft the manuscript and revising it critically. 
Received: 27 July 2015 Accepted: 5 November 2015 Published online: 11 November 2015

\section{References}

1. Parker MM, Shelhamer JH, Bacharach SL, Green MV, Natason C, Frederick TM, et al. Profound but reversible myocardial depression in patients with septic shock. Ann Intern Med. 1984;100(4):483-90.

2. Parker MM, Shelhamer JH, Natason C, Alling DW, Parillo JE. Serial cardiovascular variables in survivors and nonsurvivors of human septic shock: heart rate as an early predictor of prognosis. Crit Care Med. 1987;15(10):923-9.

3. Vieillard Baron A, Schmitt JM, Beauchet A, Auqarde R, Prin S, Page B, et al. Early preload adaptation in septic shock? A transesophageal echocardiographic study. Anesthesiology. 2001;94(3):400-6.

4. Huang SJ, Nalos M, McLean AS. Is early ventricular dysfunction or dilatation associated with lower mortality rate in adult severe sepsis and septic shock? Metaanal Crit Care. 2013;17(3):R96.

5. Nef HM, Mollmann H, Kostin S, Troidl C, Voss S, Weber M, et al. Tako-Tsubo cardiomyopathy: intraindividual structural analysis in the acute phase and after functional recovery. Eur Heart J. 2007;28(20):2456-64.

6. Ognibene FP, Parker MM, Natason C, Shelhamer JH, Parrrillo JE. Depressed left ventricular performance. Response to volume infusion in patients with sepsis and septic shock. Chest. 1988;93:903-10.

7. Hunter JD, Doddi M. Sepsis and the heart. Br J Anaesth. 2010;104(1):3-11.

8. Vincent JL, Rause C, Frank N, Contempre B, Kahn RJ. Right ventricular dysfunction in septic shock: assessment by measurements of right ventricular ejection fraction using the thermodilution technique. Acta Anaesthesiol Scand. 1989;33:34-8.

9. Kimchi A, Ellrodt AG, Berman DS, Riedinger MS, Swan HJ, Murata GH. Right ventricular performance in septic shock: a combined radionuclide and hemodynamic study. J Am Coll Cardiol. 1984;4(5):945-51.

10. Parker MM, McCarthy KE, Ogibene FP, Parrillo JE. Right ventricular dysfunction and dilatation, similar to left ventricular changes, characterize the cardiac depression of septic shock in humans. Chest. 1990;97(1):126-31.

11. Kumar A, Haery C, Parrillo JE. Myocardial dysfunction in septic shock. Crit Care Clin. 2000;16(2):251-87.

12. Jardin F, Foume T, Page B, Loubieres Y, Viellard-Baron A, Beauchet A, et al. Persistent preload defect in severe sepsis despite fluid loading: a longitudinal echocardiographic study in patients with septic shock. Chest. 1999;116(5):1354-9.

13. Papanikolaou J, Makris D, Mpaka M, Palli E, Zygoulis P, Zakynthinos E. New insights into the mechanisms involved in B-type natriuretic peptide elevation and its prognostic value in septic patients. Crit Care. 2014;18:R94.

14. Mehta NJ, Khan IA, Gupta V, Jani K, Gowda RM, Smith PR. Cardiac troponin I predicts myocardial dysfunction and adverse outcome in septic shock. Int J Cardiol. 2004;95(1):13-7.

15. Ver Elst KM, Spapen HD, Nguyen DN, Garbar C, Huyghens LP, Gorus FK. Cardiac troponins I and $T$ are biological markers of left ventricular dysfunction in septic shock. Clin Chem. 2000;46(5):650-7.

16. Ammann P, Fehr T, Minder El, Günter C, Bertel O. Elevation of troponin I in sepsis and septic shock. Intensive Care Med. 2001;27(6):965-9.

17. Bessiere F, Khenifer S, Dubourg J, Durieu I, Lega JC. Prognostic value of troponins in sepsis: a meta-analysis. Intensive Care Med. 2013;39(7):1181-9.

18. Bruni FD, Komwatana P, Soulsby ME, Hess ML. Endotoxin and myocardial failure: role of the myofibril and venous return. Am J Physiol. 1978;235(2):H150-6.

19. Cunnion RE, Schaer GL, Parker MM, Natanson C, Parrillo JE. The coronary circulation in human septic shock. Circulation. 1986;73(4):637-44.

20. Suffredini AF, Fromm RE, Parker MM, Brenner M, Kovacs JA, Wesley RA, et al. The cardiovascular response of normal humans to the administration of endotoxin. N Eng J Med. 1989;321(5):280-7.

21. Flesch M, Kilter H, Cremers B, Laufs U, Sudkamp M, Ortmann M, et al. Effects of endotoxin on human myocardial contractility involvement of nitric oxide and peroxynitrite. J Am Coll Cardiol. 1999;33(4):1062-70.

22. Parillo JE, Burch C, Shelhamer JH, Parker MM, Natanson C, Schuette W. A circulating myocardial depressant substance in humans with septic shock. Septic shock patients with a reduced ejection fraction have a circulating factor that depressed in vitro myocardial cell performance. J Clin Invest. 1985;76(4):1539-53.

23. Natanson C, Eichenholz PW, Danner RL, Eichacker PQ, Hoffman WD, Banks SM, et al. Endotoxin and tumor necrosis factor challenges in dogs simulate the cardiovascular profile of human septic shock. J Exp Med. 1989;169(3):823-32.
24. Vincent JL, Bakker J, Marecaux G, Schandene L, Kahn RJ, Dupont E. Administration of anti-TNF antibody improves left ventricular function in septic shock patients. Results of a pilot study. Chest. 1992;101(3):810-5.

25. Kumar A, Thota V, Dee L, Olson J, Uretz E, Parillo JE. Tumor necrosis factor alpha and interleukin 1 beta are responsible for in vitro myocardial cell depression induced by human septic shock serum. J Exp Med. 1996;183(3):949-58.

26. Kumar A, Brar R, Wang P, Dee L, Skorupa G, Khadour F, et al. Role of nitric oxide and CGMP in human septic serum-induced depression of cardiac myocyte contractility. Am J Physiol. 1999;276(1 Pt 2):R265-76.

27. Am S, Spurgeon HA, Sollott SJ, Talo A, Lakatta EG. 8-bromo-cGMP reduces the myofilament response to Ca2+ in intact cardiac myocytes. Circ Res. 1994;74:970-8

28. Rudiger A, Singer M. Mechanisms of sepsis-induced cardiac dysfunction. Crit Care Med. 2007;35(6):1599-608.

29. Bohm M, Kirchmayr R, Gierschik P, Erdmann E. Increase of myocardial inhibitory G-proteins in catecholamine-refractory septic shock or in septic multiorgan failure. Am J Med. 1995;98(2):183-6.

30. Crouser ED, Julian MW, Blaho DV, Pfeiffer DR, et al. Endotoxin-induced mitochondrial damage correlates with impaired respiratory activity. Crit Care Med. 2002;30(2):276-84.

31. Brealey D, Brand M, Hargreaves I, Heales S, Land J, Smolenski R, et al. Association between mitochondrial dysfunction and severity and outcome of septic shock. Lancet. 2002;360(9328):219-23.

32. Crouser ED, Jullian MW, Huff JE, Joshi MS, Bauer JA, Gadd ME, et al. Abnormal permeability of inner and outer mitochondrial membranes contributes independently to mitochondrial dysfunction in the liver during acute endotoxemia. Crit Care Med. 2004;32(2):478-88.

33. Larche J, Lancel S, Hassoun SM, Favory R, Descoster B, Marchetti P, et al. Inhibition of mitochondrial permeability transition prevents sepsis-induced myocardial dysfunction and mortality. J Am Coll Cardiol. 2006;48(2):377-85.

34. Kirov MY, Evgenov OV, Evgenov NV, Egorina EM, Sovershaev MA, Sveinbjomsson B, et al. Infusion of methylene blue in human septic shock: a pilot, randomized, controlled study. Crit Care Med. 2001;29(10):1860-7.

35. Kwok ES, Howes D. Use of methylene blue in sepsis: a systematic review. J Intensive Care. 2006;21(6):359-63.

36. Alhamdi Y, Abrams ST, Cheng Z, Jing S, Su D, Liu Z, et al. Circulating histones are major mediators of cardiac injury in patients with sepsis. Crit Care Med. 2015;43(10):2094-103.

37. Rivers E, Nguyen B, Havstad S, Ressler J, Muzzin A, Knoblich B, et al. Early goal-directed therapy in the treatment of severe sepsis and septic shock. N En J Med. 2001;345(19):1368-77.

38. ProCESS Investigators, Yearly DM, Kellum JA, Huang DT, Barnato AE, Weissfeld $L A$, et al. A randomized trial of protocol-based care for early septic shock. N Engl J Med. 2014;370(18):1683-93.

39. ARISE Investigators, ANZICS Clinical trial Group, Peake SL, Delaney A, Balley M, Bellomo R, et al. Goal-directed resuscitation for patients with early septic shock. N Engl J Med. 2014;371(16):1496-506.

40. Mouncey PR, Osborn TM, Power GS, Harrison DA, Sadique MZ, Grieve RD, et al. Trial of early, goal-directed resuscitation for septic shock. N Engl J Med. 2015;372(14):1301-11.

41. Russell JA, Walley KR, Singer J, Gordon AC, Hébert PC, Cooper DJ, et al. Vasopressin versus norepinephrine infusion in patients with septic shock. $N$ Eng J Med. 2008;358(9):877-87.

42. Dellinger RP, Levy MM, Rhodes A, Annane D, Geriach H, Opal SM, et al. Surviving sepsis campaign: international guidelines for management of severe sepsis and septic shock: 2012. Crit Care Med. 2013;41(2):580-637.

43. Mehta S, Granton J, Gordon AC, Cook DJ, Lapinsky S, Newton G, et al. Cardiac ischemia in patients with septic shock randomized to vasopressin or norepinephrine. Crit Care. 2013;17(3):R117.

44. Vincent $J \mathrm{~L}$, Roman A, Kahn RJ. Dobutamine administration in septic shock: addition to a standard protocol. Crit Care Med. 1990;18(7):689-93.

45. Gattinoni L, Brazzi L, Pelosi P, Latini R, Tognoni G, Pesenti A, et al. A trial of goal- oriented hemodynamic therapy in critically ill patients. ScvO2 Collaborative Group. N Eng J Med. 1995;333(16):1025-32.

46. Hayes MA, Timmins AC, Yau EH, Paiazzo M, Hinds CJ, Waston D. Elevation of systolic oxygen delivery in the treatment of critically ill patients. N Eng J Med. 1994;330(24):1717-22.

47. Wilkman E, Kaukonen KM, Pettila V, Kuitunen A, Varpula M. Association between inotrope treatment and 90-day mortality in patients with septic shock. Acta Anaesthesiol Scand. 2013;57(4):431-42. 
48. Hernandez G, Bruhn A, Luengo C, Regueira T, Kattan E, Fuentealba A, et al. Effects of dobutamine on systemic, regional and microcirculatory perfusion parameters in septic shock: a randomized, placebo-controlled, double-blind, crossover study. Intensive Care Med. 2013:39(8):1435-43.

49. Lyte M, Freestone PP, Neal CP, Olson BA, Haigh RD, Baystone R, et al. Stimulation of Staphylococcus epidermidis growth and biofilm formation by catecholamine inotropes. Lancet. 2003;361(9352):130-5.

50. Morelli A, Ertmer C, Westphal M, Rendberg S, Kampmeiter T, Ligges S, et al. Effect of heart rate control with esmolol on hemodynamic and clinical outcomes in patients with septic shock: a randomized clinical trial. JAMA. 2013;310(16):1683-91.

51. Zangrillo A, Putzu A, Monaco F, Oriani A, Frau G, De Luca M, et al. Levosimendan reduces mortality in patients with severe sepsis and septic shock: a meta-analysis of randomized trials. J Crit Care 2015; doi: 10.1016/ j.jcrc.2015.05.017. [Epub ahead of print]

52. Solomon DB, Minneci PC, Deans KJ, Feng J, Eichacker PQ, Banks SM, et al. Effects of intra-aortic balloon counterpulsation in a model of septic shock. Crit Care Med. 2009;37(1):7-18.

53. Nakamura K, Doi K, Inokuchi R, Fukuda T, Hiruma T, Ihiii T, et al. Endotoxin adsorption by polymyxin B column or intraaortic balloon pumping use for severe septic cardiomyopathy. Am J Em Med. 2013;31(5):893. e1-3.

54. Payen DM, Guilhot J, Launey Y, Lukaszewicz AC, Kaaki M, Veber B, et al. Early use of polymyxin B hemoperfusion in patients with septic shock due to peritonitis: a multicenter randomized control trial. Intensive Care Med. 2015;41(6):975-84.

55. Pořízka M, Kopecký P, Prskavec T, Kunstýř J, Rulišek J, Balík M. Successful use of extra-corporeal membrane oxygenation in a patient with streptococcal sepsis: a case report and review of literature. Prague Med Rep. 2015;116(1):57-63.

56. Fujisaki N, Takahashi A, Arima T, Mizushima T, Ikeda K, Kakuchi $\mathrm{H}$, et al. Successful treatment of Panton-Valentine leukocidin-expressing Staphylococcus aureus-associated pneumonia co-infected with influenza using extracorporeal membrane oxygenation. In Vivo. 2014;28(5):961-5.

57. Endo A, Shiraishi A, Aiboshi J, Hayashi Y, Otomo Y. A case of purpura fulminans caused by Haemophilus influenzae complicated by reversible cardiomyopathy. J Intensive Care. 2014;2(1):13.

58. Bréchot $N$, Luyt CE, Schmidt $M$, Leprince $P$, Trouillet JL, Léger $P$, et al. Venoarterial extracorporeal membrane oxygenation support for refractory cardiovascular dysfunction during severe bacterial septic shock. Crit Care Med. 2013;41(7):1616-26

59. Hagiwara S, Murata M, Aoki M, Kaneko M, Oshima K. Septic shock caused by Klebsiella oxytoca: an autopsy case and a survival case with driving extracorporeal membrane oxygenation. Hippokratia. 2013;17(2):171-3.

60. Firstenberg MS, Abel E, Blais D, Louis LB, Steinberg S, Sai-Sudhakar C, et al. The use of extracorporeal membrane oxygenation in severe necrotizing soft tissue infections complicated by septic shock. Am Surg. 2010;76(11):1287-9.

61. MacLaren G, Cove M, Kofidis T. Central extracorporeal membrane oxygenation for septic shock in an adult with H1N1 influenza. Ann Thorac Surg. 2010;90(3):e34-5.

62. Vohra HA, Adamson L, Weeden DF, Haw MP. Use of extracorporeal membrane oxygenation in the management of septic shock with severe cardiac dysfunction after Ravitch procedure. Ann Thorac Surg. 2009;87(1):e4-5

63. MacLaren G, Pellegrino V, Butt W, Preovolos A, Salamonsen R. Successful use of ECMO in adults with life-threatening infections. Anaesth Intensive Care. 2004;32(5):707-10.

64. Combes A, Brodie D, Bartlett R, Brochard L, Brower R, Conrad S, et al. Position paper for the organization of extracorporeal membrane oxygenation programs for acute respiratory failure in adult patients. Am J Respir Crit Care. 2014;190(5):488-96.

\section{Submit your next manuscript to BioMed Central and take full advantage of:}

- Convenient online submission

- Thorough peer review

- No space constraints or color figure charges

- Immediate publication on acceptance

- Inclusion in PubMed, CAS, Scopus and Google Scholar

- Research which is freely available for redistribution

Submit your manuscript at www.biomedcentral.com/submit 